\title{
The stability of clay using volcanic ash of Mount Sinabung North Sumatera and sugarcane bagasse ash with cbr and uct value
}

\author{
Ika Puji Hastuty ${ }^{1, *}$, Roesyanto $^{1}$, and Giovanni Ramadhany ${ }^{1}$ \\ ${ }^{1}$ Departement of Civil Engineering, Universitas Sumatera Utara, Indonesia
}

\begin{abstract}
Soil is the fundamental material that is extremely as the place of establishment of a structure or construction, both building and road constructions. However, not all soil is well used in the constructions field, as there are several types of soil that are problematic in terms of both the soil bearing capacity and deformation. The clay with carrying capacity and low shear strength needs to stabilized in order to meet the technical requirements to be used as sub grade. The add materials that are typically used for soil stabilization are cement, lime or a mixture of two or three of the added materials. In this study, the added material use volcanic ash of Mount Sinabung at North Sumatera and sugarcane bagasse ash. The purpose of this study was to determine an index value of properties as the result of the addition of $4 \%$ volcanic ash and variations in content of bagasse ash on clay and then to determine the compressive strength for maximum testing UCT (Unconfined Compression Test) and understand the value of CBR (California Bearing Capacity) as the consequence of the addition of a stabilizing agent, as well as optimum level of addition of bagasse ash. The result showed that the original soil sample has the water content $12.35 \%$, specific gravity of 2.65 , liquid limit of $46.73 \%$ and plasticity index of $26.44 \%$. The compressive strength value of $1.38 \mathrm{~kg} / \mathrm{cm}^{2}$. Base on the USCS classification, the soil sample including the type CL while base on AASHTO classification, soil samples are include this A-7-6 type. After the soil is stabilized with a wide variety of sugarcane bagasse ash content value obtained the largest unconfined compression test in $4 \%$ addition level volcanic ash $+10 \%$ sugarcane bagasse ash is equal to $5.1 \mathrm{~kg} / \mathrm{cm}^{2}$ and the result California Bearing capacity value on the optimal mix of $4 \%$ volcanic ash $+4 \%$ sugarcane bagasse ash is equal to $13.91 \%$.
\end{abstract}

\section{Introduction}

The entire buildings are closely related to the soil, because the soil can be used as building material and as foundation of a building establish. In each implementation of the development, investigation of the soil is the initial step to conduct in order to determine whether the soil at the construction site meets the requirements of planning, namely stability, deformation and density. Soil stabilization is the mixing of soil with certain

\footnotetext{
*Corresponding author: ikapuji@gmail.com
} 
substances to improve the technical properties of the soil in order to meet certain requirements. Clay is one type of soil that is frequently stabilized. This is due the clay is very hard in dry condition and more plastic on medium level of water content, but then water content level is high, the clay will be cohesive and very soft, cause large volume change due the influence of water and prompts the soil to expand and swelling in a relative short period of time. This characteristic is the one that becomes the reason of the necessary of the stabilization process, so that it can be corrected in order to increase to carrying capacity of the soil $[1,2,4]$

There are three ways of soil stabilization process, i.e. mechanical, physical and chemical process. The stabilization process utilized in this study is chemical process which was conducted by adding the mixed ingredients in the form Volcanic ash of Mount Sinabung North Sumatera and sugarcane bagasse ash. Sugarcane bagasse ash is derived from the burning of bagasse ash which changes chemically and if left without cleaning that can harm the environment [5]. Volcanic ash is one of the natural substances that are formed in the earth that later becomes volcanic material that is ejected into the air during an eruption. Volcanic ash is not soluble in water, very rough and corrosive.

Based on the function of volcanic ash from Mount Sinabung as the natural material expelled from the volcano, although it can result in damages to the environment, it also has other more profitable usages. The content of $\mathrm{SiO}_{2}$ is the main constituent element in the forming of cement, therefore the volcanic ash has the pozzolan characteristic. The pozzolan characteristic has the behaviour of binding other minerals that exist in clay so that it hardens in a certain period of time. The content of silica $\left(\mathrm{SiO}_{2}\right)$ that is found in volcanic ash is $82.4 \%$ and $\mathrm{CaO}$ is $5.10 \%$. In sugarcane bagasse ash, the content of $\mathrm{SiO} 2$ is $71 \%$ and $\mathrm{CaO}$ is $3.4 \%$.

The purpose of this study is to understand the physical characteristic of the original soil, knowing the influence of the addition of volcanic ash and sugarcane bagasse ash towards the soil stability and also to discover the optimum mixture which contributes to the value of the Unconfined Compression Test (UCT) and the largest California Bearing Capacity (CBR) value in the clay with is stabilized with volcanic ash and sugarcane bagasse ash.

\section{Research Methods}

\subsection{Preparation work}

Finding the literature that are related to the clay that is stabilized, about volcanic ash and sugarcane bagasse ash and the literature regarding the Unconfined Compression Test (UCT) and California Bearing Ratio (CBR).

\subsection{Material Preparation}

\subsubsection{The collection of Soil Sample}

The soil sample that is used in this study is from Patumbak, Deli Serdang, North Sumatera. The soil is categorized as the clay with low to medium level of water content.

\subsubsection{The procurement of volcanic ash}

The volcanic ash that was used is sourced from the eruption of Mount Sinabung. Taken from Desa Tiganderkat Tanah Karo, North Sumatera, Indonesia. The utilized ash is the ash that has passed Sieve No. 200. Based on material test result it is discovered that the chemical composition of the volcanic ash is $\mathrm{SiO}_{2} 82.40 \%, \mathrm{Al}_{2} \mathrm{O}_{2}$ is $4.52 \%$ and $\mathrm{CaO}$ is $5.10 \%$.

\subsubsection{The procurement of sugarcane bagasse ash}

The sugarcane bagasse ash that was used is the ash obtain from the sugarcane bagasse ash waste that was burned to be ash. Taken from Factory Kuala Madu, Langkat, North Sumatera, Indonesia. The utilized ash is the ash that has passed Sieve No. 200. Based on 
material test result it is discovered that the chemical composition of the volcanic ash is $\mathrm{SiO}_{2}$ $71 \%, \mathrm{Al}_{2} \mathrm{O}_{2}$ is $1.90 \%$ and $\mathrm{CaO}$ is $3.40 \%$.

\subsection{Implementation of Testing}

The testing was conducted in two parts that are the testing for the original soil and the testing for the soil that has been added with the mixture of stabilizer material. Laboratory analysis at Research Institution of University of Sumatera Utara, laboratory of Soil Mechanic, Department of Civil Engineering, University of Sumatera Utara.

\section{Research Results}

Table 1. Data of physical properties of the soil, bagasse ash and Volcanic ash

\begin{tabular}{|c|c|c|c|c|}
\hline No & Testing & Soil & Bagasse ash & Volcanic ash \\
\hline 1 & Water Content & $17.89 \%$ & - & $2.62 \%$ \\
\hline 2 & Specific Grafity & 2.65 & 2.55 & - \\
\hline 3 & Liquid Limit & $45.49 \%$ & Non Plastic & Non Plastic \\
\hline 4 & Plastic Limit & $15.19 \%$ & Non Plastic & Non Plastic \\
\hline 5 & Plasticity Index & $30.30 \%$ & Non Plastic & Non Plastic \\
\hline 6 & Sieve Analysis No. 200 & $52.28 \%$ & $10.51 \%$ & $13.40 \%$ \\
\hline
\end{tabular}




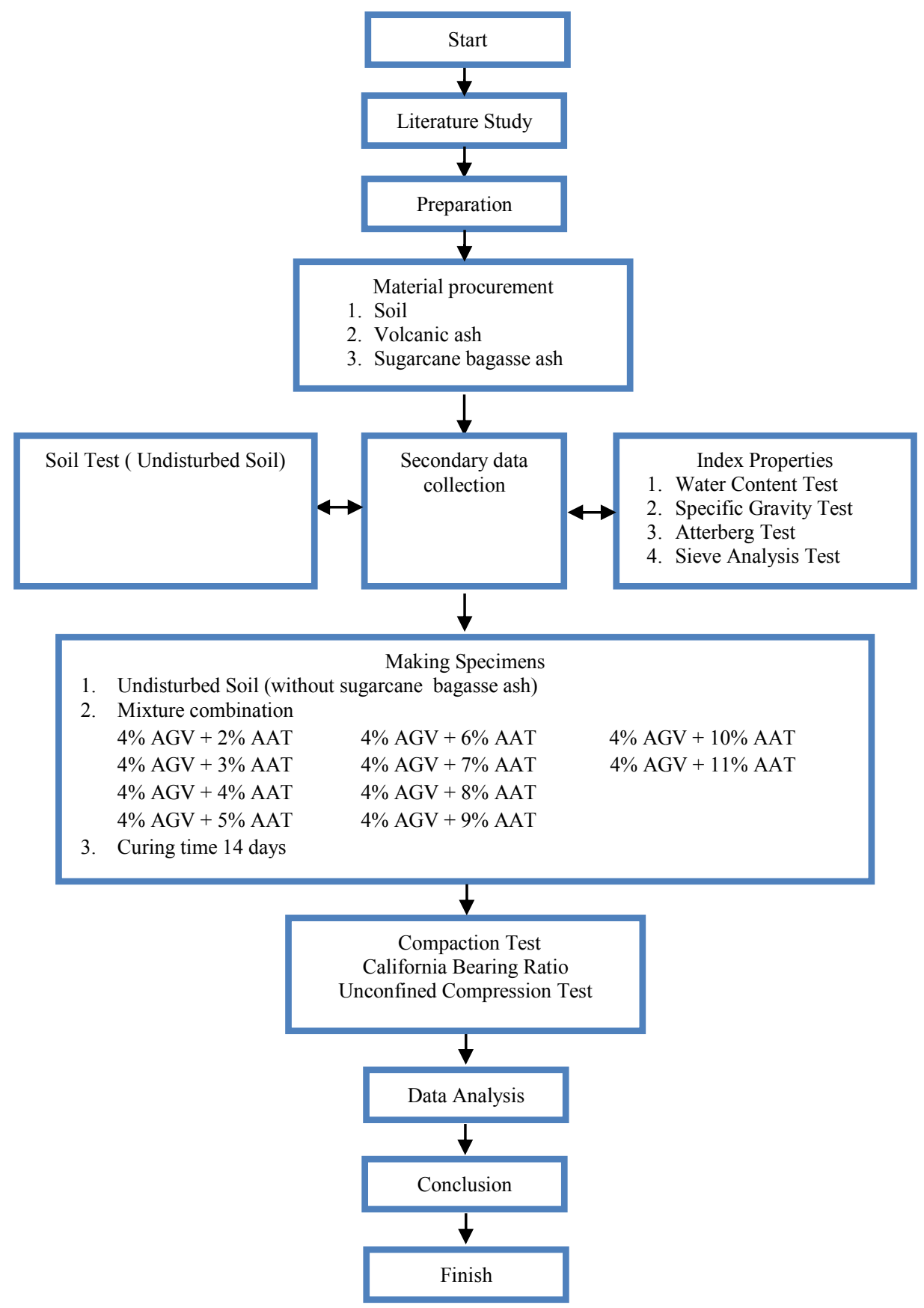

Figure 1. Research Flow Diagram 
Base on USCS classification, the sample of the soil is included in CL (Clay - Low Plasticity) type which is inorganic clay with plasticity level of low to medium. Base on the AASHTO classification, the sample of the soil is categorized as A-7-7 type.

\subsection{The Test of Physical and Chemical Characteristics of Soil with Stabilizer Material}

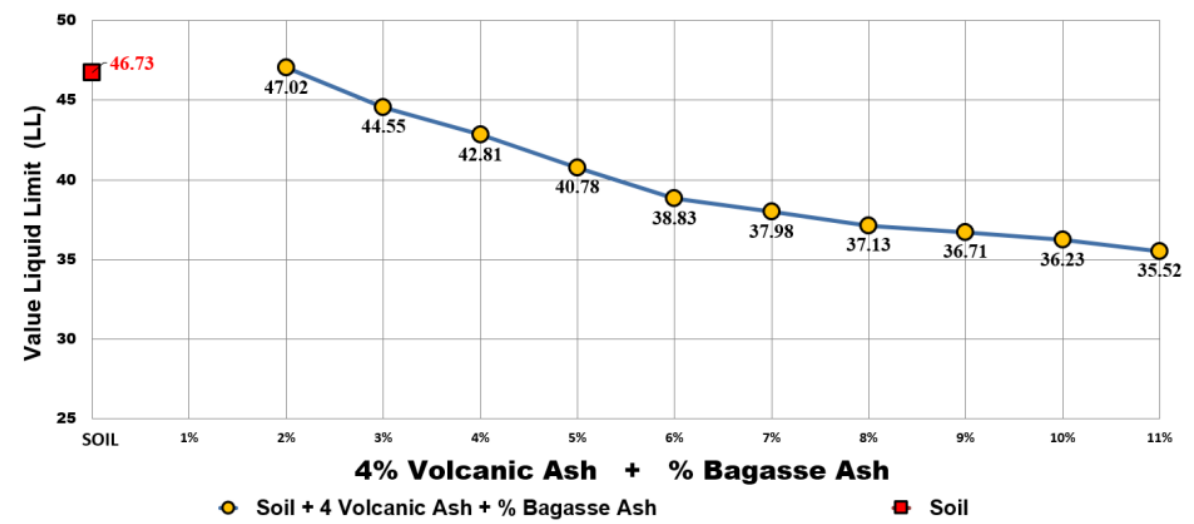

Figure 2. Correlative Graph Between Liquid Limit (LL) and Mixture Variation

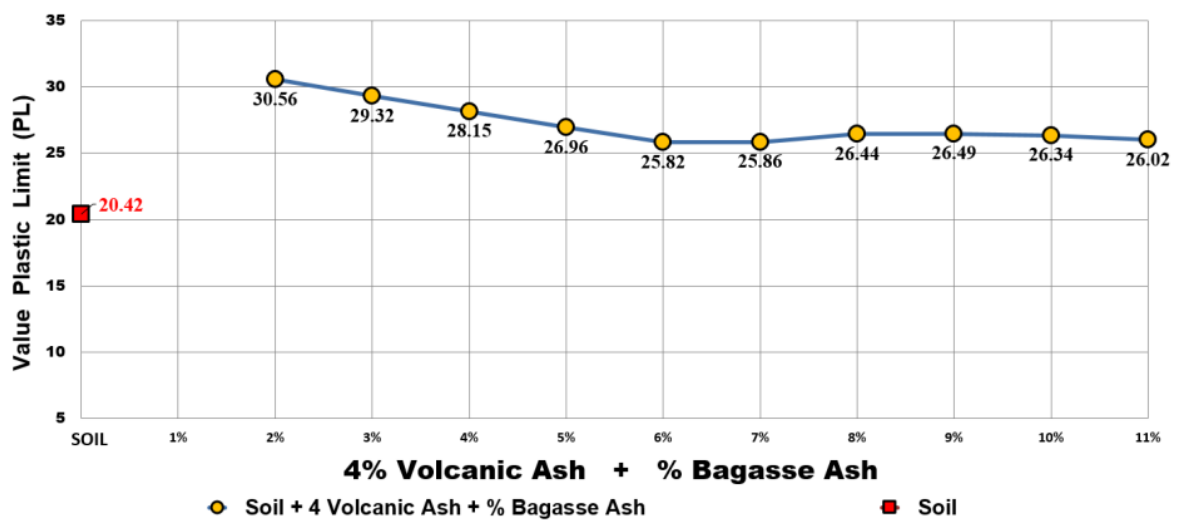

Figure 3. Correlative Graph Between Plastic Limit (PL) and Mixture Variation 


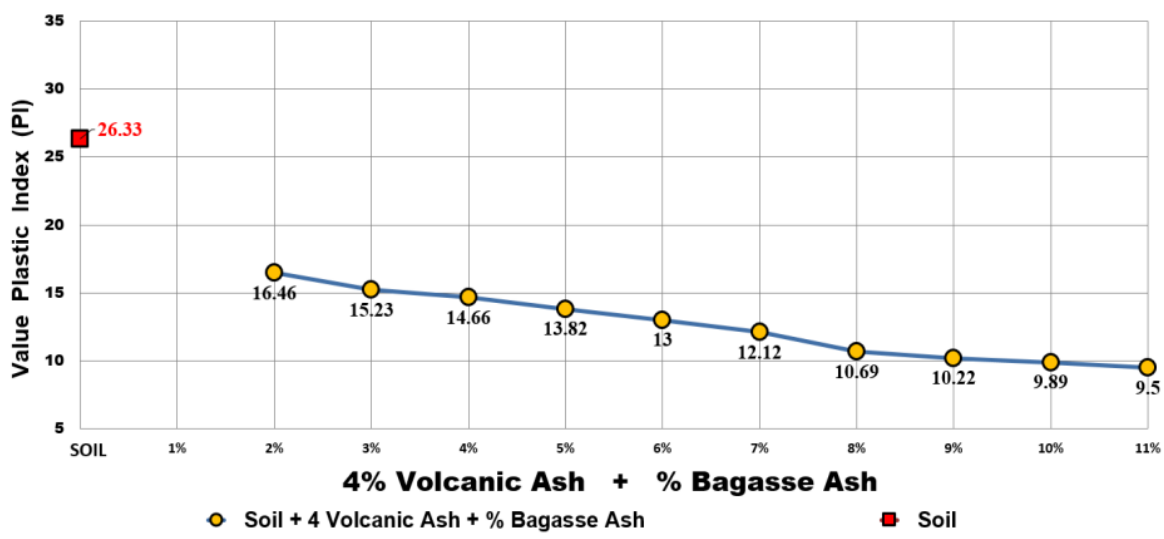

Figure 4. Correlative Graph Between Plasticity Index (PI) Mixture Variation

Figure 2 exhibits that the addition of stabilizer material results in the decrement of Liquid Limit. The higher percentage is the baggase ash, the lower is the liquid limit. Meanwhile, Figure 3 shows the increasing Plastic Limit. On Figure 4, it is the graph of Plasticity Index value of each variation of mixture. The decreasing of Plasticity Index value could reduce the expansion and the shrinkage of the soil.

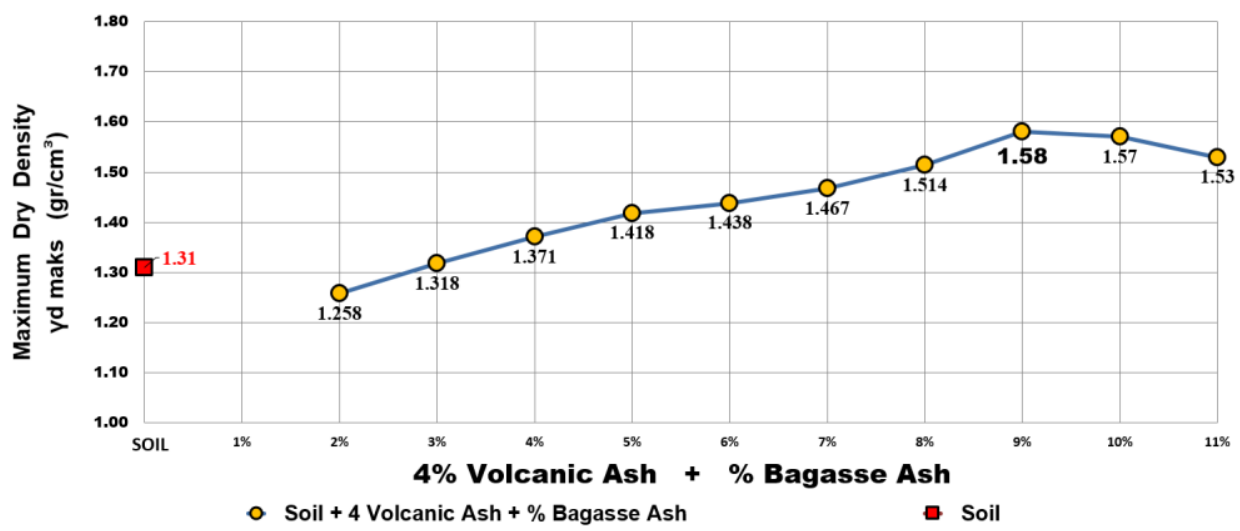

Figure 5. Correlative Graph between maximum Dry Bulk Density of the Soil and Mixture Variation 


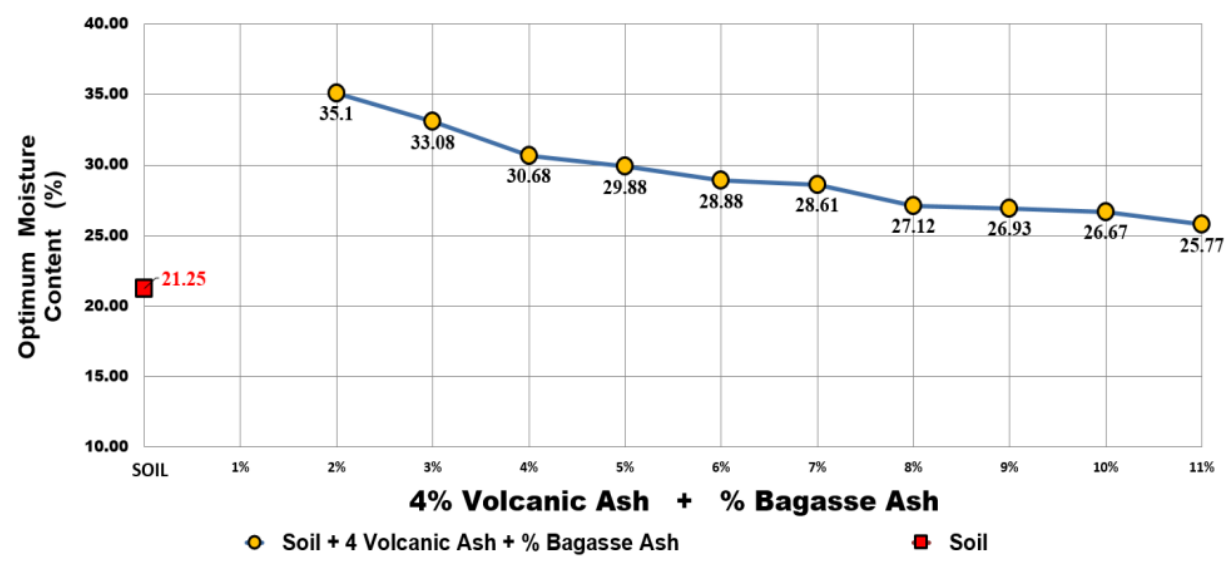

Figure 6. Correlative Graph between Optimum Water Content Level of Soil and Mixture Variation

Figure 7 owed that the Correlative Graph of UCT Value and the Variation of 4\% volcanic ash and 2\%-11\% bagasse ash Addition Percentage. Compressive strength which used $4 \%$ volcanic ash and $10 \%$ bagasse ash had the highest which was $5.1 \mathrm{~kg} / \mathrm{cm}^{2}$.

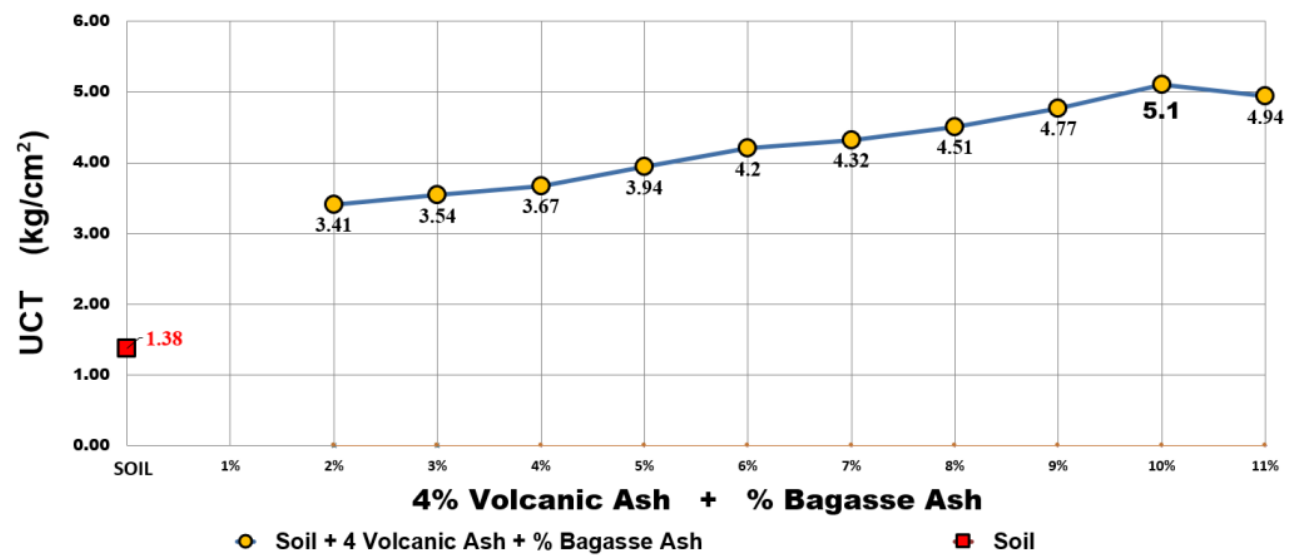

Figure 7. Correlative Graph of UCT Value and the Variation of $4 \%$ volcanic ash and $2 \%$ $11 \%$ bagasse ash Addition Percentage 


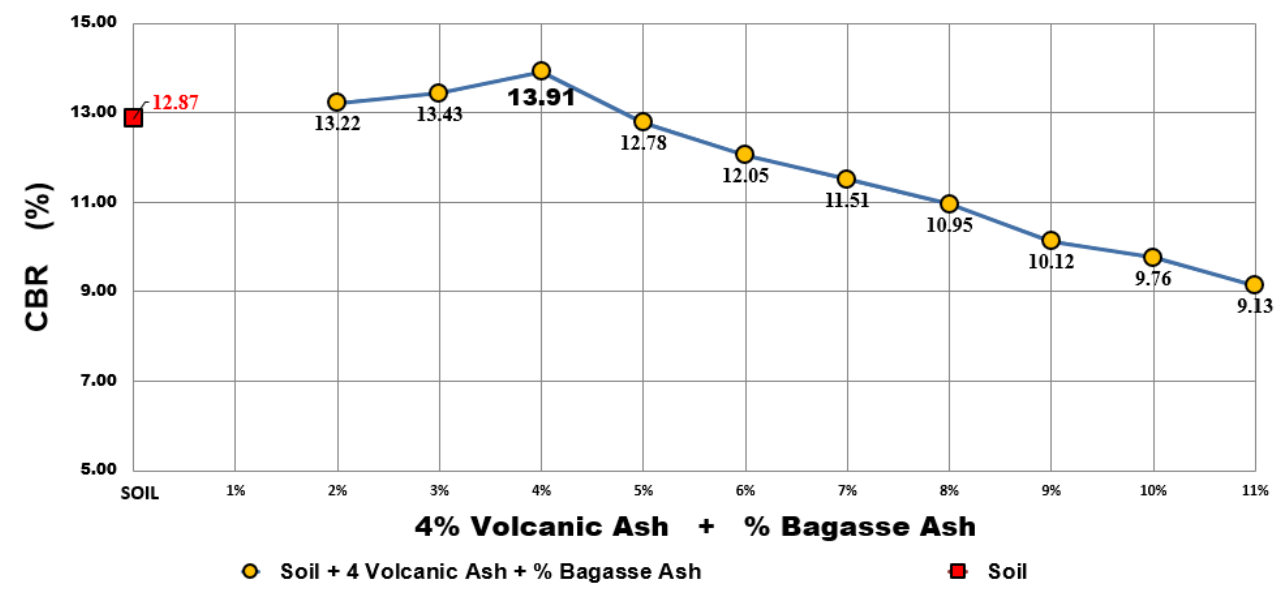

Figure 8. Correlative Graph of CBR Value and the Variation of 4\% volcanic ash and 2\%$11 \%$ bagasse ash Addition Percentage

Meanwhile, the result of the California Bearing Ratio Test is displayed in the graph that is included in Figure 8. The influence of the mixture of baggase ash in the clay towards the strength of the clay can be viewed from the CBR test result in unsoaked condition, with each soil variation that has been mixed with the volcanic ash stabilization material and bagasse ash within 14 days curing time. It can be seen that the increasing of the percentage of baggase ash mixture causes the CBR value to increase to the level of baggase ash percentage of $4 \%$ had the highest CBR value is $13.91 \%$

\section{Conclusion}

Based on the conducted study in influence of the addition of stabilizer material of volcanic ash of Mount Sinabung and sugarcane bagasse ash towards clay with the mixture content that is determined and curing time of 14 days, it can be concluded that the type of soil that is used according to USCS is Clay - Low Plasticity (CL) and according to AASTHO is A7-6 type. The biggest compressive strength value happens to addition level of $4 \%$ volcanic ash $+10 \%$ bagasse ash is $5.1 \mathrm{~kg} / \mathrm{cm}^{2}$ and the CBR laboratory test result in the optimal CBR value in the mixing of $4 \%$ volcanic ash $+4 \%$ bagasse ash with CBR value of $13.91 \%$

Financial support for the research was provide by University of Sumatera, North Sumatera

\section{References}

1. Bowles,J.E, Physical and Geotechnical Properties of Soil, 2 (1991)

2. Das Sobhan, Principles of Geotechnical Engineering, 8 (2012)

3. Hardiyatmo, H, Mekanika Tanah, 1 (2002)

4. I.P.Hastuty. I.S.Sembiring,M.I Abidin, The Utilization of Volcanic Ash and High Rusk Ash as Material Stabilization in Clay by Unconfined Compression Test (UCT) and California Bearing Ratio (CBR), IOP Conf Series 180 (2017) 